\title{
INTRAHEPATIC CHOLANGIOCARCINOMA DETECTION AND SEGMENTATION OF IMAGES USING DEEP LEARNING TECHNIQUES
}

\author{
Muhammad Shoaib Kareem \\ Department of CS\&IT \\ Riphah International University, \\ Lahore, Pakistan \\ Mohsin Shahzad \\ Department of Electrical \\ Engineering, \\ Islamia University of Bahawalpur, \\ Pakistan
}

\author{
Zeeshan Ahmad \\ Department of Electrical \\ Engineering, \\ Islamia University of Bahawalpur, \\ Pakistan \\ Mohsin Bashir \\ Department of Computer Science, \\ Riphah International University, \\ Lahore, Pakistan \\ Fareeha Zahoor \\ Department of Electrical Engineering, \\ Islamia University of Bahawalpur, \\ Pakistan
}

\author{
Talha Farooq Khan \\ Department of Computer Science, \\ Islamia University of Bahawalpur, \\ Pakistan \\ Fawwad Hassan Jaskani \\ Department of Computer \\ Engineering, Islamia University of \\ Bahawalpur, \\ Pakistan
}

\begin{abstract}
Intrahepatic cholangiocarcinoma is a form of cancer that forms in the cells of the bile ducts, both inside and outside of the liver. Cholangiocarcinoma and bile duct cancer are two words that are often used interchangeably to describe the same disease. Therefore, we have proposed an intelligent Hepatoma detection system. So, the main purpose of this research is to develop and implement an automated method that will help to detect and classify the Liver Cancer disease by processing hepatomic images. We have used liver-tumor-segmentation dataset for the testing our proposed methodology, it contains 130 images of Liver Cancer patients. We have applied pre-processing techniques on these images such as morphological filtering, in order to enhance images from input data for post processing. After obtaining the resultant image we have applied slicing. We have used UNets (modified form of convolutional Neural Network) for classification purpose with ResNet34, 50 and 100 architecture for downsampling and upsampling of shifted pixels. The proposed technique provides a sophisticated diagnosis and classification accuracy when compared with previous techniques. The parameter we used to validate the performance of our proposed technique is Top-N accuracy. Our proposed method shows the accuracy of about $\mathbf{9 9 . 8 \%}$.
\end{abstract}

Keywords - Deep Learning, Computer Vision, Liver Diseases

\section{INTRODUCTION}

Hepatoma is one of the deadliest cancers in the world [1]. Detection in the initial stages is crucial for patients to survive. Liver Cancer, as well as Hepatoma, Basal Cell Carcinoma (BCC) and Cutaneous Squamous Cell Carcinoma (SCC) have one of the main global occurrences of any type of cancer [2]. According to the statistics of Pakistan, 428 new cases of Hepatoma ware detected and 313 deaths were recorded in 2018 [3]. Liver Cancer is the 5th most common cancer in the United Kingdom (UK). Sixteen thousand patients detected and 2285 deaths in 2016 with this cancer [3]. The survival rate can be improved if cancer is detected at an initial stage. [4]. The pie chart of the most common types of Liver Cancer is shown in Figure 1 [5]-[7]. The Non-Hepatoma Liver Cancers (NMSC) consists of BCC and SCC. Keratinocyte Carcinomas (KCs) is very communal. In the UK, approximately 142,000 novel cases were identified, with $20 \%$ SCC and $80 \%$ BCC. Alike to Hepatoma, the occurrence of $\mathrm{KC}$ has increased over the current years, with a rise of $61 \%$ if compared with the last 10 years [8] [9] [10]. The different stages of Hepatoma cancer can be differentiated by the depth of penetration of cancer cells as shown in Figure below: 


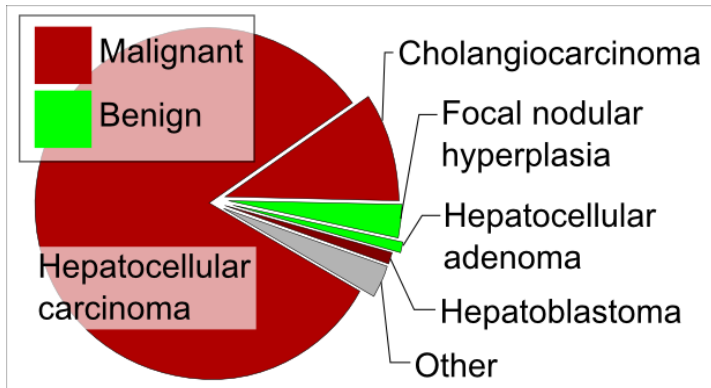

Figure 1 Pie chart of liver tumors

Openly accessible datasets are attained from numerous different imaging hospitals and research organizations with different data features. [11]. In this research used the computer-aided dermatologic procedures with a novel set of apparatuses for the pre-processing of the training dataset. These are pre-processing steps moderates the above-mentioned data facets negotiating deep-network performance in the practice. The pre-processing involves the cleansing and slicing steps. The process of data cleansing/purification is like removal of blockings (e.g. noises and rulers from the pictures) depending on the well-organized tumor segmentation technique. The procedure of slicing of data is 2 folded. It contains balancing of data over the artificial hepatomic images which carrying out further data. Tools that were used for data cleansing and slicing ultimately improve the performance of deep learning-based classifications for tumors. Even though all researchers have an excessive understanding of the health-related images. Several may not familiar with ML and how it can be utilized in medical imaging interpretation and analysis tasks [12]. The main goal of ML in healthcare is not to replace the physician but replace the physician which did not use ML. The following definition of ML is generally known in the globe: If an ML procedure is practiced to a data or set of data (Liver Cancerous images) and some information about this data (benign or malignant), then the system algorithm can acquire from the data that is going train and what type of predictions it gives from learned data (whether a dissimilar image is showing benign/malignant liver tissue) [12][13]. If the system enhances its parameters like its performance increases, further test cases are detected appropriately, then it is viewed to be learning that function.

In more than 3000 liver diseases affect 2 in every 3 people. It is very difficult to diagnose. $50 \%$ of the diagnoses in a public hospital is incorrect. The dermatology problem is extremely costly because of unnecessary visits, tests and treatments to general practitioners because of incorrect diagnoses. Most people have also no access to a dermatologist. So, ML and AI can be used to support image classification using Deep Neural Networks (DNN). When an image, data, or information of liver is input to a machine it recognizes the morphology of the liver disease and produces some kind of different diagnosis as the earlier prediction. To provide decision support this can be faster and better than the other traditional methods. ML and $\mathrm{AL}$ improve the knowledge and skills in primary care and substitution detection in cost.

There are two types of Liver Tumors, a malignant hepatoma and a non-malignant. Malignant Hepatoma Liver Cancer has a harmful effect because it can spread and affect other areas of the body's liver. Throughout the case of the deadliest diseases such as hepatoma, early diagnosis plays a crucial role in discovering the possibility of recovery. At the initial level, a medical professional must discern a commonly diagnosed tumor from moderate benign tumors.

Liver Cancer has impacted numerous human lives and early stage diagnosis of Liver Cancer plays a major part in assessing the likelihood of survival. We hope that we will use advanced Deep Learning techniques to promote early detection and provide timely information to people who may be at risk. This method is not always reliable and is not meant to replace clinical treatment. The core contributions of this research are as described below:

Some pre-processing techniques are performed to create a great worth and stable images with test sets constructed only from images of tumors. For noise removal, we adapted the morphological filtering to shrink image regions and Conversion into Greyscale as it is difficult to operate an RGB image. We have performed a filtering process named Black Hat, as it converts an image including the objects of the input image. We have applied thresholding on images as it is a segmentation process. This is done to separate object pixels from background pixels. After that, in this research reconstruct the missing part of images using image Inpaint.

To balance the imbalanced data, we have used slicing techniques to increase the training dataset. In research this we have used FASTAI and UNets models for the classification of our model

Most of the work done can classify liver tumors however limited work is done on the classification of multiple diseases. In recent researches, various techniques have been introduced by the researchers to diagnose and differentiate Hepatoma from other Liver Cancers. The existing literature is generally classified into supervised and unsupervised learning techniques [14]-[19].

$\underline{\text { In }}$ [20] author proposed a method that had four steps based on the ABCD rule. 1) Pre-processing step: contains filtering and contrast enhancement procedures. 2) Segmentation for detection of the tumor. 3) Feature extraction step: to create computations on 4 parameters which were diameter, asymmetry, and color and border irregularity. 4) Classification step: performed on the summation of the 4 extracted parameters and multiplied by weights which produced the Total Histology Value (TDV). At last, the tumor was categorized into benign and malignant. The proposed method was executed in the MATLAB software and the experimentation was based on the PH2 dataset containing concerned Hepatoma Liver Cancer. Outcomes and assumptions were made based on the experimentation; the accuracy of the applied method is $90 \%$, 


\section{International Journal of Engineering Applied Sciences and Technology, 2021 \\ Vol. 6, Issue 4, ISSN No. 2455-2143, Pages 124-136 \\ Published Online August 2021 in IJEAST (http://www.ijeast.com)}

which reproduces its reliability. Other advanced techniques of image processing can be used for the detection of liver tumors.

In [21] author presented a CNN based method to distinguish Liver Cancer. The main dataset which is utilized to train CNN had 97 patients, which were composed of the International Liver Imaging Collaboration (ISIC). To compensate for the deficiency of data/information for training the proposed CNN method, a Generative Adversarial Network (GAN) was intended to make artificial Liver Cancer pictures. The classification rate of the proposed trained CNN lacking the obtained artificial images was near 53\%. After the addition of the artificial scans to the main database, the classification rate of the model was improved to $71 \%$. By using other classes of Machine learning, the classification of liver tumors can be enhanced.

In [22] author proposed a method for early detection of Liver Cancer. Some scientists have established a mechanism using Machine Learning procedures to categorize liver tumors from Histology scans of human liver. They presented a Convolutional Neural Network (CNN) to process their model. They used liver-tumor-segmentation dataset as an input to CNN. They described that CNN performs good image processing and feature extraction. It can be applied to each feature image location. Their results showed the good classification of malignant Hepatoma and benign melanocytic nevi. Their CNN model gave an accuracy of $87.64 \%$, specificity $81.66 \%$, sensitivity $96.40 \%$, F1 score $86.36 \%$ and precision $78.21 \%$. Their Result showed that there is a need for enhancement in specificity, F1 score and precision. This can be done by using more classification models.

In [23] author presented an approach for the classification of liver tumors based on UNets, Convolutional Neural Networks (CNNs). They worked on UNets and gave a modified UNets used for the classification of liver tumors. They had used the LIVER SEGMENTATION DATASET 130 CTSCANS database for the training of the model. Data slicing and data sampling techniques were used in their work for enhancing the competence of the classifier. Their results showed that their modified UNets model had attained higher accuracy of $83.93 \%$, $84 \%$ sensitivity, $81 \%$ specificity and $80 \% \mathrm{~F} 1$ score as compared to the outdated UNets model. The integration of their model and more pre-processing techniques can improve the classification rate of liver tumors.

The efficiency of data slicing was described by authors in [24], in which the pre-trained GoogleLeNet was tuned well. They obtained the advanced outcomes for the International Symposium on Biomedical Imaging (ISBI) Hepatoma Classification Challenge held in 2016 [25]. They faced the individualities when handling with an unbalanced, small and biological record. For this purpose, they explored different committees that were held on the 'CNN's trained through the ISBI challenge'. Training dataset improved by traditional image processing algorithms and image warping techniques (image warping used to correct distortion in images) directed by professionals. These professionals had vast information about the axis of the tumor and improved the ultimate classifier invariance to communal Hepatoma variations. The final CNN layers were chosen with the finest accuracy on the validation dataset. Initially, the results were attained by training measures through GoogLeNet ILSVC, which was pre-determined on a larger dataset. This type of well tuning overcome the training time and over fitting detected in all trials as predictable.

In [26] authors presented DL based methods to resolve the difficulties in liver tumor investigation employing a hepatomic image containing liver tumor. They trained and evaluated their proposed models on standard benchmark data from ISIC [27]. Dataset pictures were resized at a fixed range of $227 \times 227$. CNN was used as a DL framework for the automatic detection of Hepatoma. Their CNN contained Convolutional Layer, Batch Normalization Layer, ReLU Layer, Max Pooling Layer, Fully connected layer, Softmax Layer and a classification layer. In the end, their proposed technique attained $96.67 \%$ accuracy and compared their results with [28]. Their experimental tests approved on clinical data showed that the classification performance via DL-based features accomplishes better than the existing techniques.

In [29] authors presented a technique in which they performed segmentation and classification for automated detection of liver tumors. Their proposed model consists of two steps. The first stage influences on a Fully Convolutional Network (FCN). The FCN learned the inhomogeneous and complex liver tumor features. Another stage proposed an innovative FCN-based DenseNet architecture. This architecture is made up of dense blocks that were merged and linked through the concatenation approach and transition layer. This architecture also used hyperparameters optimization procedures to overcome network complication and progress computing efficiency. They had used a publicly available dataset (Liver Segmentation Dataset $130 \mathrm{CT}$ scans) for the evaluation of their model. As a result, they achieved classification with $98 \%$ accuracy, 99\% of AUC score and $98.5 \%$ recall respectively. They described that their model can overcome the complexity when dealing with deep features of liver tumors.

In [30] authors took part in the ISIC challenge for the classification of liver tumors. They engrossed on three definite types of tumors: Hepatoma, Benign Nevi, and Seborrheic Keratosis. The task was a two-fold classification: Hepatomaothers and Seborrheic Keratosis-others. The main task of their study was to produce an additional impulse in the scores of AUC. For this, they depend on the pre-trained ResNet-101 and InceptionV4 models. The highest outcomes were attained by depending on encompassing the dataset. Both models were attained via pre-processing of data. It involves the normalization of each image, data slicing and utilizing a mixture of the predictive outcomes of dissimilar models as an 


\section{International Journal of Engineering Applied Sciences and Technology, 2021 \\ Vol. 6, Issue 4, ISSN No. 2455-2143, Pages 124-136 \\ Published Online August 2021 in IJEAST (http://www.ijeast.com)}

input for any high-level learning system like SVM classifier. Their results showed an AUC of $80.7 \%$ and the classification prediction $84.5 \%$ for Liver Cancer tumors. This demonstration further strengthens the decision of using dissimilar models in an additional learning structure.

In [31] authors presented their work to the Computer Vision Journal [32]. They discovered a way to use autoencoder for assisting classification (benign vs. malignant) of tumors. They proposed a semi-supervised technique for a de-noising adversarial auto-encoder to challenge classification with an inadequate categorized dataset and manipulating a large unlabeled dataset. They presented the comprehensive construction of the CNN and the ssDAAE model that was utilized as a reference point. CNN contains four convolution layers. At the output of individually layer ReLU non-linearity model is functional before being nourished to the succeeding one. Without the last linear layer, CNN makes the encoder of the ssDNA. Lastly, a sigmoidal layer is functional to the previous output layer of the system. To estimate reproducibility, they retrain individually from their models, the ssDAAE, sAAE, sDAAE and ssAAE, eight times and estimate them on the testing set. Their outcomes showed that the further information which may be erudite from the un-labelled information is beneficial for classification [33]-[37].

Table 1 Supervised techniques for Liver Cancer detection and classification

\begin{tabular}{|c|c|c|c|c|}
\hline Ref & Technique & Dataset & Parameters & End Result \\
\hline [20] & $\mathrm{ABCD}$ rule & PH2 & Accuracy & Liver tumors. \\
\hline [21] & CNN, GAN & ISIC & Accuracy & Liver tumor. \\
\hline [22] & $\mathrm{CNN}$ & $\begin{array}{c}\text { LIVER-TUMOR- } \\
\text { SEGMENTATIO } \\
\mathrm{N}\end{array}$ & $\begin{array}{c}\text { Accuracy, } \\
\text { Sensitivity } \\
\text { Specificity } \\
\text { Prediction }\end{array}$ & $\begin{array}{c}\text { Malignant } \\
\text { Hepatoma } \\
\text { and benign } \\
\text { melanocytic } \\
\text { nevi. }\end{array}$ \\
\hline [38] & $\begin{array}{l}\text { TL, CNN, } \\
\text { SVM }\end{array}$ & ISIC & $\begin{array}{l}\text { Accuracy, } \\
\text { Sensitivity } \\
\text { Specificity }\end{array}$ & $\begin{array}{l}\text { Prediction of } \\
\text { liver tumor. }\end{array}$ \\
\hline [39] & DL & $\begin{array}{c}\text { LIVER-TUMOR- } \\
\text { SEGMENTATIO } \\
\mathrm{N}\end{array}$ & AUC & $\begin{array}{c}\text { Liver } \\
\text { Cancer. }\end{array}$ \\
\hline [40] & $\begin{array}{c}\text { CNN, } \\
\text { AlexNet, } \\
\text { VGG16, } \\
\text { ResNet-18, } \\
\text { SVM }\end{array}$ & ISIC & ROC & liver tumors \\
\hline [23] & $\mathrm{CNN}$ & $\begin{array}{c}\text { LIVER-TUMOR- } \\
\text { SEGMENTATIO } \\
\mathrm{N}\end{array}$ & $\begin{array}{l}\text { Sensitivity } \\
\text { Specificity } \\
\text { and F1 } \\
\text { Score }\end{array}$ & Liver tumor. \\
\hline [26] & $\mathrm{CNN}$ & ISIC & Accuracy & Liver tumors. \\
\hline [24] & $\begin{array}{l}\text { CNN, Image } \\
\text { warping }\end{array}$ & ISIC, ISBI & Accuracy & $\begin{array}{l}\text { Hepatoma } \\
\text { classification }\end{array}$ \\
\hline
\end{tabular}

\begin{tabular}{|c|c|c|c|c|}
\hline [29] & $\begin{array}{c}\text { Fully } \\
\text { Convolution } \\
\text { al Network } \\
\text { (FCN) }\end{array}$ & $\begin{array}{c}\text { LIVER-TUMOR- } \\
\text { SEGMENTATIO } \\
\mathrm{N}\end{array}$ & $\begin{array}{l}\text { Accuracy, } \\
\text { AUC, } \\
\text { recall }\end{array}$ & Liver tumors. \\
\hline [30] & CNN, SVM & ISIC & AUC & $\begin{array}{l}\text { Liver tumor } \\
\text { classification }\end{array}$ \\
\hline [31] & $\begin{array}{c}\text { CNN, } \\
\text { ssDAAE, } \\
\text { sAAE, } \\
\text { sDAAE and } \\
\text { ssAAE }\end{array}$ & ISIC & $\begin{array}{l}\text { RSD, } \\
\text { AUC }\end{array}$ & $\begin{array}{c}\text { Benign and } \\
\text { malignant } \\
\text { liver tumor. }\end{array}$ \\
\hline [41] & $\begin{array}{c}\text { CNN, DL, } \\
\text { TL }\end{array}$ & $\begin{array}{c}\text { LIVER-TUMOR- } \\
\text { SEGMENTATIO } \\
\mathrm{N}\end{array}$ & $\begin{array}{l}\text { F1-Score, } \\
\text { Recall, } \\
\text { Precision, } \\
\text { Accuracy. }\end{array}$ & Liver tumors. \\
\hline [42] & $\begin{array}{l}\text { DL, TL, } \\
\text { Softmax, } \\
\text { AlexNet }\end{array}$ & PH2 dataset & $\begin{array}{c}\text { Accuracy, } \\
\text { specificity } \\
\text { and } \\
\text { sensitivity }\end{array}$ & $\begin{array}{l}\text { Hepatoma } \\
\text { Liver } \\
\text { Cancer. }\end{array}$ \\
\hline [43] & $\overline{D N N}, \mathrm{DL}$ & ISIC and DermNet & $\begin{array}{l}\text { AUC and } \\
\text { accuracy }\end{array}$ & $\begin{array}{c}\text { Liver } \\
\text { diseases. }\end{array}$ \\
\hline
\end{tabular}

In [44] author proposed a process that had three steps for Hepatoma classification. These three steps were spanning preprocessing, features mining and classification. They acquired dataset from Dermatology Information System and DermQuest. After the pre-processing of data, they used a Discrete Wavelet Transform (DWT) to extract the features. In their approach classification was based on a weighted auto-encoder model that allows every AE-layer to be trained on the features it attained from the previous layer, in an unsupervised manner. After that with integrated a Softmax layer is on topmost of this work to acquire classification. Their outcomes showed that less accuracy of about $89.3 \%$ with texture analysis and SAE is used. While they used DWT with SAE, their model gives 94\% accuracy. Hence, their model showed the best accuracy for Hepatoma diagnosis. Kharazmi et al. [45] presented a computer-aided system for the detection and localization of Cutaneous Vasculature using DL. They proposed a feature learning method which was based on Stacked Sparse AutoEncoders (SSAE), for inclusive detection of cutaneous vessels. The individually training image was separated into minor patches with or without having vasculature. An SSAE was intended to pick up hidden features from data in an unsupervised way. High-level erudite features were then nourished in a classifier which categorized individually every patch in the presence or absence of vasculature and confined vessels inside the tumor. The proposed architecture established higher performance with the detection accuracy of $95.4 \%$ on a diversity of vessel outlines; outdoing other methods by attaining the uppermost predictive rate of $94.7 \%$. Their projected CAD architecture can help as a decision-making system to the dermatologists for further precise diagnosis, particularly in Tele-dermatology requests in inaccessible areas. By extracting more deep features of liver tumor datasets, classification can be improved.

Farooq et. al. [46] proposed research that contains two foremost phases. Images were pre-processed to eliminate the clutters so 
creating a refined variety of training pictures was the first phase. To attain this, a sharpening filter was applied afterward a noise removal procedure. Dissimilar image quality dimension metrics as well as Energy Ratio/ Ratio of Squared Norms (L2RAT), Peak Signal to Noise (PSNR), Maximum Absolute Squared Deviation (MXERR) and Mean Square Error (MSE) were used to compare the total image quality formerly and later applying pre-processing processes. Their outcomes from the abovementioned image metrics proved that image quality does not cooperate however it is progressed by applying the preprocessing procedures. Another phase of the proposed work includes DL methods that played a bossy role in precise, robust and accurate classification of the liver tumor. This was done by using two DL models: UNets and Inception-v3. The experimental outcomes demonstrate prominent enhancement in training and validation accuracy. Though, the Inception-v3 was able to attain improved validation accuracy therefore it was lastly selected to estimate it on test data. Hence, the ultimate test accuracy employing the Inception-v3 system was $86 \%$. More precise pre-processing can provide good classification accuracies

\section{PROPOSED Algorithm}

the dataset and performance parameters used for experimentation and validation of the proposed model are introduced. The publicly available Liver-Tumor-Segmentation dataset [47] is used for validation of the proposed method. The total number of images in the dataset is 130 (CT Scans). Out of which $30 \%$ images are of Hepatoma Cancerous while $70 \%$ images are of Normal Lesion of Liver.

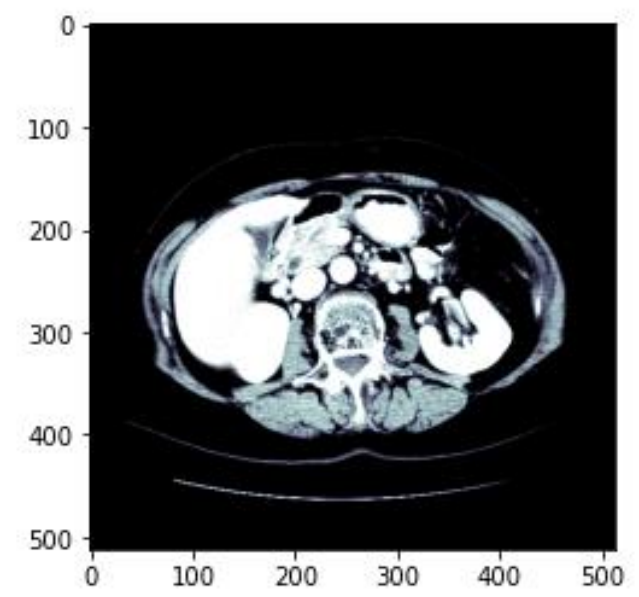

Figure 2 Image from Dataset

Performance metrics i.e. accuracy, Area under Curve (AUC), sensitivity and specificity are used for validation of the procedure.

In this research, the Liver Tumor Segmentation dataset has been used. In this dataset total 140 CT Scan images are present which contains liver as well as lesion images. Lesions are the abnormal cells present in a liver. Basically these lesions are commonly found in almost every person, these abnormal cells are call cyst, or non-cancerous tumors. But when these cyst are becoming cancerous they will produce a malignant or benign tumors in the liver. In Malignant tumor part other than liver may be affected by these lesions but in benign only liver will be affected. Following figure shows the sample lesion of liver images taken from [48].

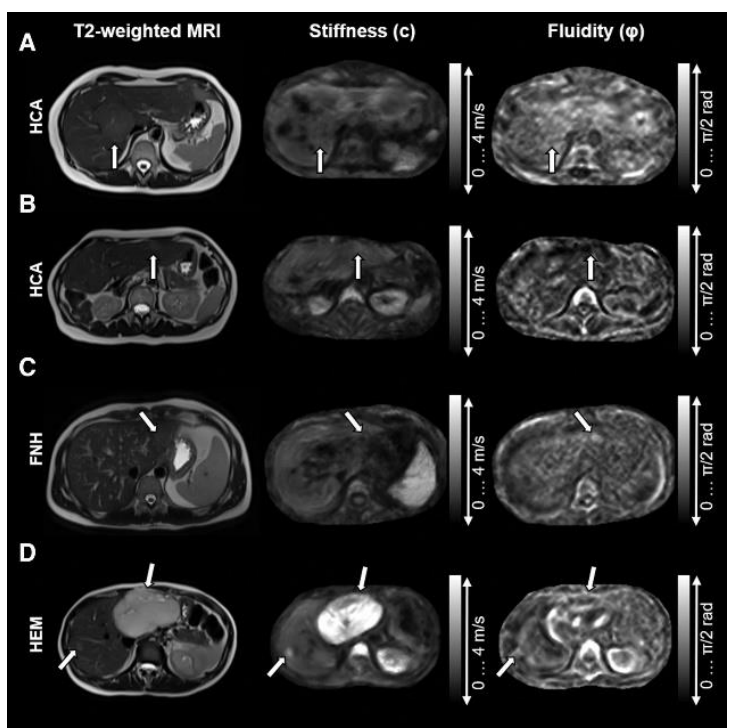

Figure 3 Lesions of Liver

These lesions can be detected from different imagining techniques such as Medical Resonance Imaging (MRI), Computed Tomography (CT) and PET. In our research the main objective is to predict the tumor in the segmented image of Liver. For this purpose, the images in the dataset discussed above has been taken as an input.

For image as an input, one can install Opencv library for image processing and computer vision in Python. For this research, the author has imported important libraries for both i.e. Image Processing and Computer Visions. The images of datasets are in DICOM format, in order to process the images easily in a digitized form.

Table 2 Libraries for Preprocessing of Data

\begin{tabular}{|l|l|}
\hline $\begin{array}{l}\text { Pre- } \\
\text { processing } \\
\text { Libraries }\end{array}$ & Description \\
\hline Numpy & Numpy used for mathematical operations \\
\hline Pandas & Pandas use for csv files and input datasheets \\
\hline OS & OS use for directory and location \\
\hline nibabel & $\begin{array}{l}\text { This is neuroimaging library for medical } \\
\text { imaging in python }\end{array}$ \\
\hline Cv2 & $\begin{array}{l}\text { Computer vision is the second version of } \\
\text { OpenCV. It is used for implementing } \\
\text { computer vision techniques on dataset }\end{array}$ \\
\hline tqdm & $\begin{array}{l}\text { This library is used for support of nested } \\
\text { loops in python }\end{array}$ \\
\hline
\end{tabular}




\begin{tabular}{|l|l|}
\hline Image.io & $\begin{array}{l}\text { This library is used for reading and writing } \\
\text { for wide range of image data }\end{array}$ \\
\hline ipywidgets & This library used for HTML widget files \\
\hline Matplotlib & $\begin{array}{l}\text { This library is used for plotting and sub } \\
\text { plotting }\end{array}$ \\
\hline PIL & $\begin{array}{l}\text { Python Imaging Library is used for python } \\
\text { imaging }\end{array}$ \\
\hline
\end{tabular}

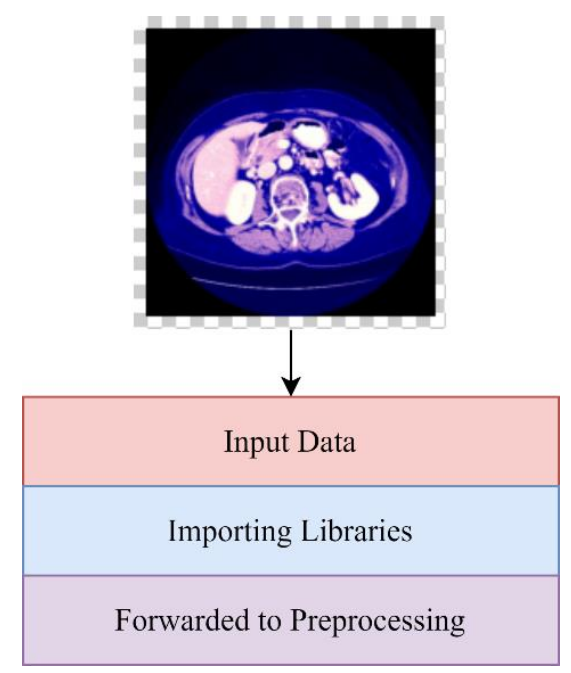

Figure 4 Input Data for Preprocessing Techniques

A U-Net is a deep convolutional neural network architecture designed for the segmentation of biomedical images. For tasks where the output is close in size to the input and output requires the spatial resolution, U-Nets were detected to be quite efficient. This makes them ideal for segmentation masks and image processing/generation including super-resolution or colorization.

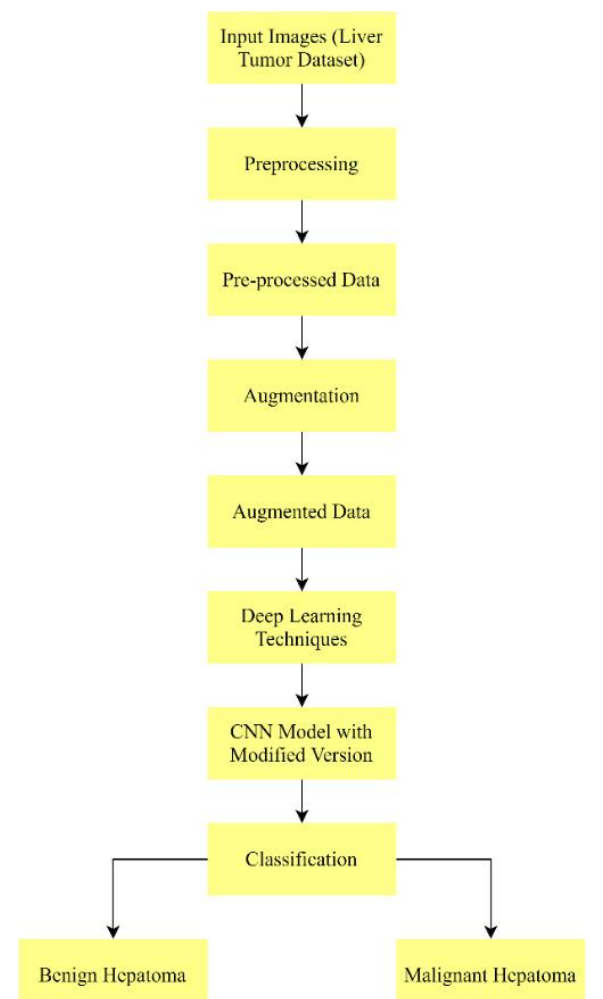

Figure 5 Block diagram of the proposed method

Hepatomic images are mostly exposed to noise mainly due to bad light, noise and air bubbles. It includes noise removal like (noise removal from image and resizing of image) and shading removal. These steps provide a way for further steps. we find useful information from the pre-processing of metadata. Exploratory data analysis is also lying in this section. Medical images are most prone to noise such as noise. In general, preprocessing techniques can handle the noise of the images [49] and machine learning techniques learn to avoid these noises while making classification and predictions, though their ability to learn is conditioned upon the availability of large training data. In the case of medical Hepatomic images datasets, which are mostly imbalanced datasets, the Deep Learning models are easily susceptible to over fitting, i.e. they utilize visual hints such as noise as indicators of the cancer category.
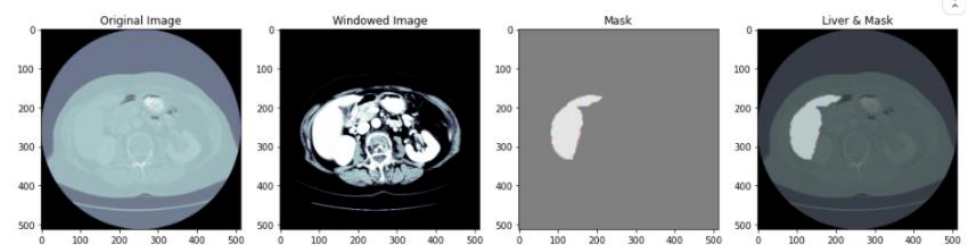

Figure 6 Preprocessing of dataset 
International Journal of Engineering Applied Sciences and Technology, 2021

Vol. 6, Issue 4, ISSN No. 2455-2143, Pages 124-136

Published Online August 2021 in IJEAST (http://www.ijeast.com)

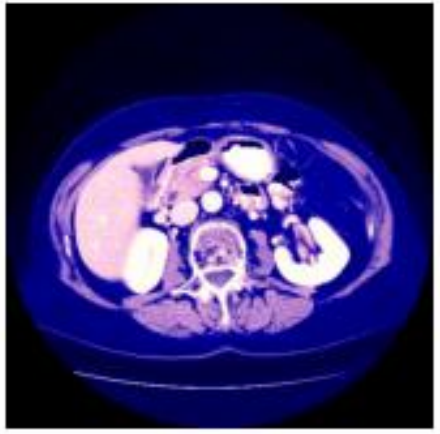

Figure 7 Preprocessed data

After the process of artificial expanding of the data set, an augmented dataset is received that dataset ready to use for learning in my model. This data improves my model performance as mention above in the slicing section.

We have to train our model to find the optimal learning rate. Set my training set to the quality when training is fastest, as well as the loss is still diminishing. We have built a feature that uses our feedback as an anchor and sweeps via a range to find the best minima. The optimal learning rate of the model is shown in figure below. And training of our model and the losses during the training are shown in figure 19 and 20. We can see that losses decrease exponentially as the training of the number of batches increases.
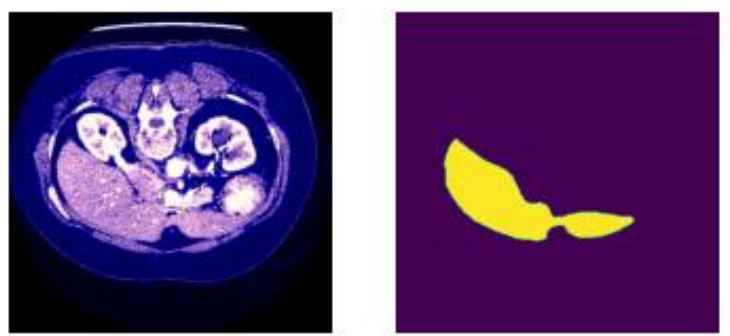

Figure 8 Training of our model
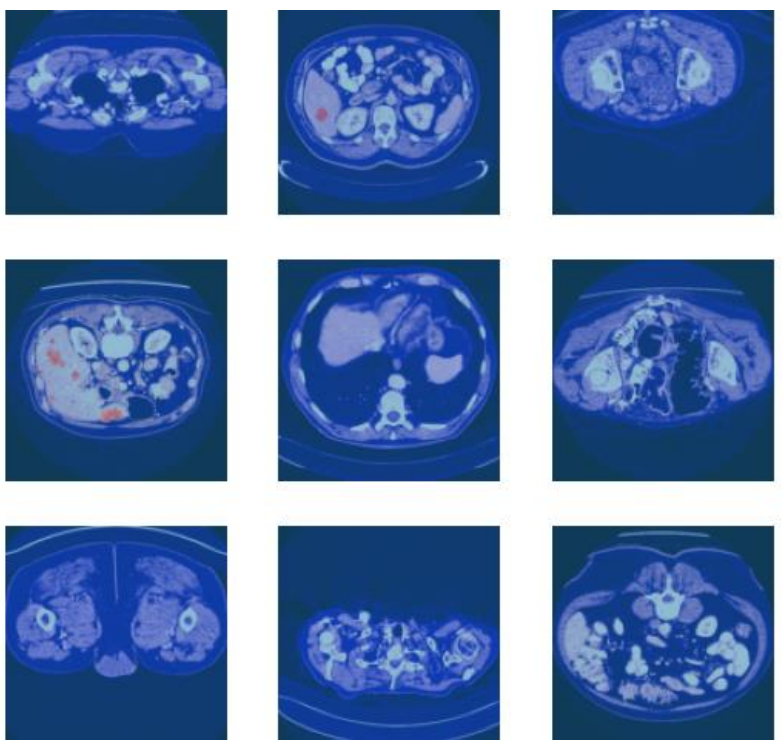

Figure 9 Processing of UNets and Model Training Images

\section{EXPERIMENTAL RESULTS}

Classification performance of a model on a test data or a set of data. Test data for which the accurate values are known are used. The CM itself is comparatively simple to know, but the associated terminology can be unclear. The CM of our build model is shown in Fig. below.

\begin{tabular}{|c|c|c|c|c|c|c|c|c|}
\hline & & & & nf & on & at & & \\
\hline & akiec & 10 & 4 & 1 & 0 & 1 & 1 & 0 \\
\hline & bcc & 1 & 17 & 0 & 0 & 0 & 1 & 0 \\
\hline & bkl & 3 & 0 & 28 & 0 & 7 & 11 & 0 \\
\hline 㐏 & df & 0 & 0 & 0 & 1 & 0 & 3 & 0 \\
\hline & mel & 0 & 1 & 1 & 0 & 13 & 10 & 0 \\
\hline & nv & 0 & 1 & 6 & 1 & 5 & 473 & 0 \\
\hline & vasc & 0 & 0 & 0 & 0 & 0 & 1 & 6 \\
\hline & & $\frac{\underline{U}}{\mathrm{I}}$ & ¿ & 总 & 告 & 异 & $\geqq$ & 的 \\
\hline & & & & & dic & & & \\
\hline
\end{tabular}

Figure 10 Confusion Matrix of our model

Take a glance at a few of the items which were most challenging for our model to detect. Figure above displays some of the different selection that was difficult to detect in our model. At every sub-image in fig. below, some parameters are shown. These parameters are:

Prediction: tumor predicted by the model

Actual: Actual tumor that the model could not predict. Loss: Losses occur during predicting the random image. Probability: Probability of the model to predict the tumor correctly. 
International Journal of Engineering Applied Sciences and Technology, 2021

Vol. 6, Issue 4, ISSN No. 2455-2143, Pages 124-136

Published Online August 2021 in IJEAST (http://www.ijeast.com)
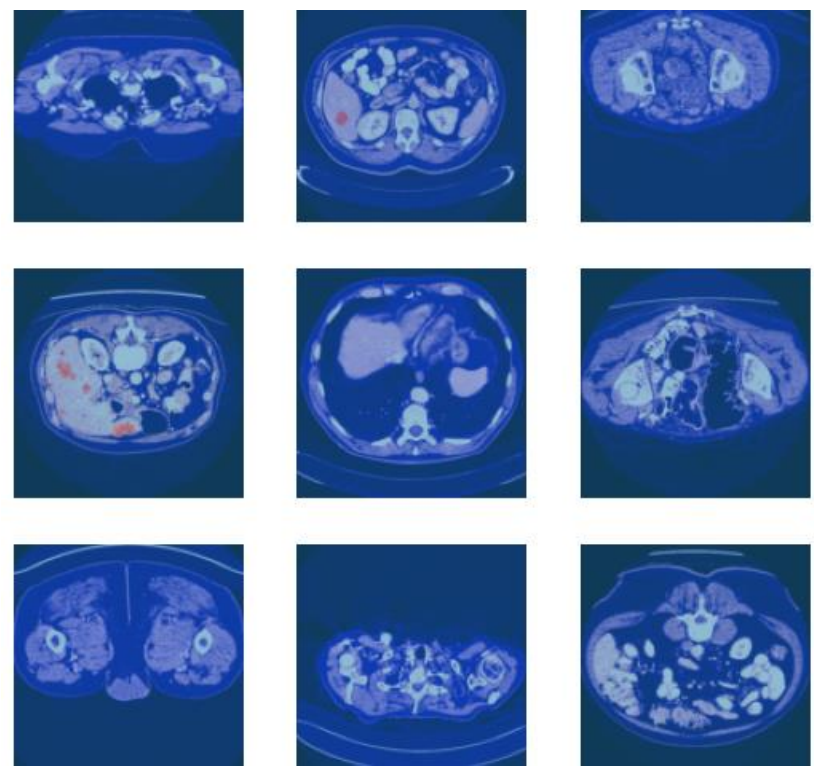

Figure 11 Predicted Images masks of original liver images

Table 3 Performance of prediction of UNets Model

\begin{tabular}{|l|l|l|l|l|l|}
\hline $\begin{array}{l}\text { Epo } \\
\text { ch }\end{array}$ & $\begin{array}{l}\text { Foregrou } \\
\text { nd } \\
\text { Accurac } \\
\mathrm{y}\end{array}$ & $\begin{array}{l}\text { Loss } \\
\text { Validati } \\
\text { on }\end{array}$ & $\begin{array}{l}\text { Loss } \\
\text { Traini } \\
\mathrm{ng}\end{array}$ & $\begin{array}{l}\text { Accuracy } \\
\text { Validatio } \\
\mathrm{n}\end{array}$ & $\begin{array}{l}\text { Learni } \\
\text { ng } \\
\text { Rate }\end{array}$ \\
\hline 1 & 0.991 & 0.93 & 0.34 & $\begin{array}{l}0.992323 \\
21\end{array}$ & 0.12 \\
\hline 2 & $\begin{array}{l}0.99234 \\
23\end{array}$ & 0.432 & 0.63 & $\begin{array}{l}0.993397 \\
774\end{array}$ & 0.11 \\
\hline 3 & $\begin{array}{l}0.99433 \\
4\end{array}$ & 0.443 & 0.4 & $\begin{array}{l}0.966635 \\
3\end{array}$ & 0.10 \\
\hline 4 & $\begin{array}{l}0.99543 \\
34\end{array}$ & 0.63 & 0.6 & $\begin{array}{l}0.986876 \\
6\end{array}$ & 0.08 \\
\hline 5 & $\begin{array}{l}0.97653 \\
3\end{array}$ & 0.23245 & 0.21 & $\begin{array}{l}0.988875 \\
644\end{array}$ & 0.08 \\
\hline
\end{tabular}

In figure above let's consider the first sub-image. The model predicted it as abnormal with showing red color having segments with some kind of tumors in it. The losses occur during the prediction of this random image 7.65 and the probability to predict this random sample was 0. Finally, now it's time to test the model. I provided some random images one by one to the build model and let's look at the confidence predictions of some samples. Since our main focus was to detect Hepatoma liver tumors. The 'prediction interval' guesses in which value a future individual reflection will fall, whereas a 'confidence interval' displays the likely value of ranges related to the statistical constraint of the information, i.e., the mean of the population. So, I will see some random images of Hepatoma and see the confidence predictions of the model. Two sample images are shown in figure 23 and 24 with a $100 \%$ confidence level.
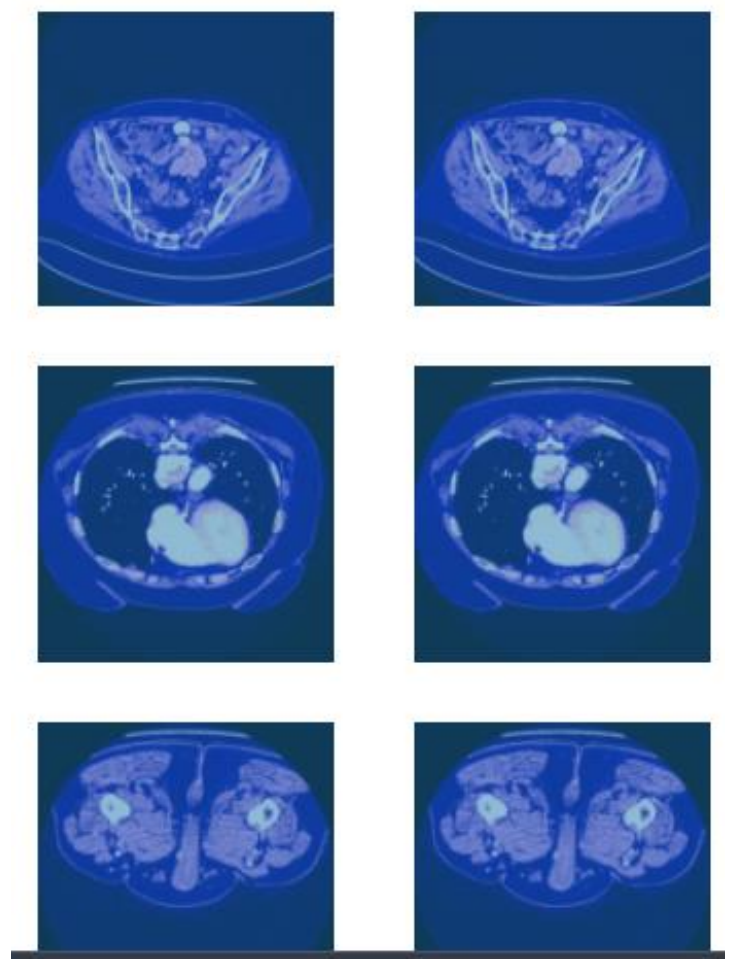

Figure 12 Target vs Predicted images

In the above Figures, the randomly provided images were of Hepatoma liver tumor and the model predicted it correctly with a $99.9 \%$ confidence level. There are also some images that the model was not able to predict it with full confidence In the above figures, the model predicted the Hepatoma correctly but the confidence level was not much impressive. It is not as good as it should be but still, it's not very bad at all. These images show the model predictably the Hepatoma correctly but the confidence level was approx. $85 \%$ and $68 \%$ respectively.

Similarly, my model does not only detect Hepatoma, but it can also detect other liver tumors with an impressive confidence level.

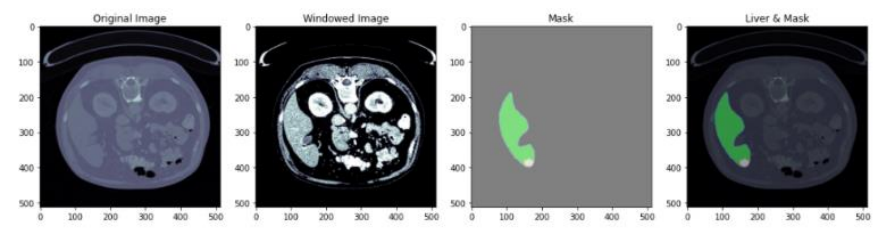

Figure 13 Model Testing 
International Journal of Engineering Applied Sciences and Technology, 2021

Vol. 6, Issue 4, ISSN No. 2455-2143, Pages 124-136

Published Online August 2021 in IJEAST (http://www.ijeast.com)

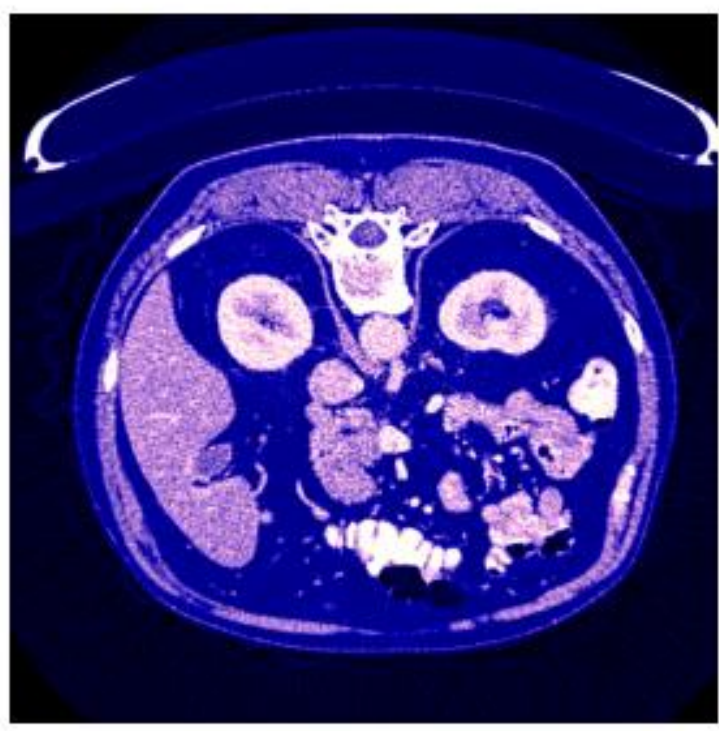

Figure 14 Preprocessed Test Images

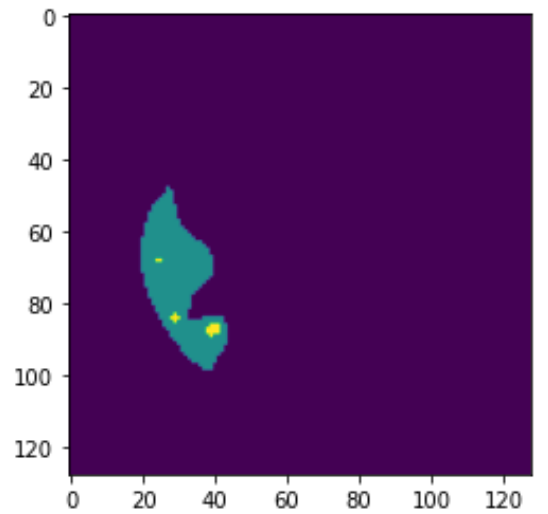

Figure 15 Segmented Tumor in ROI

We have used 3 models of ResNet with UNets in order find the best one model of ResNet which can fit with the unit to make a mask of a tumor with much accuracy

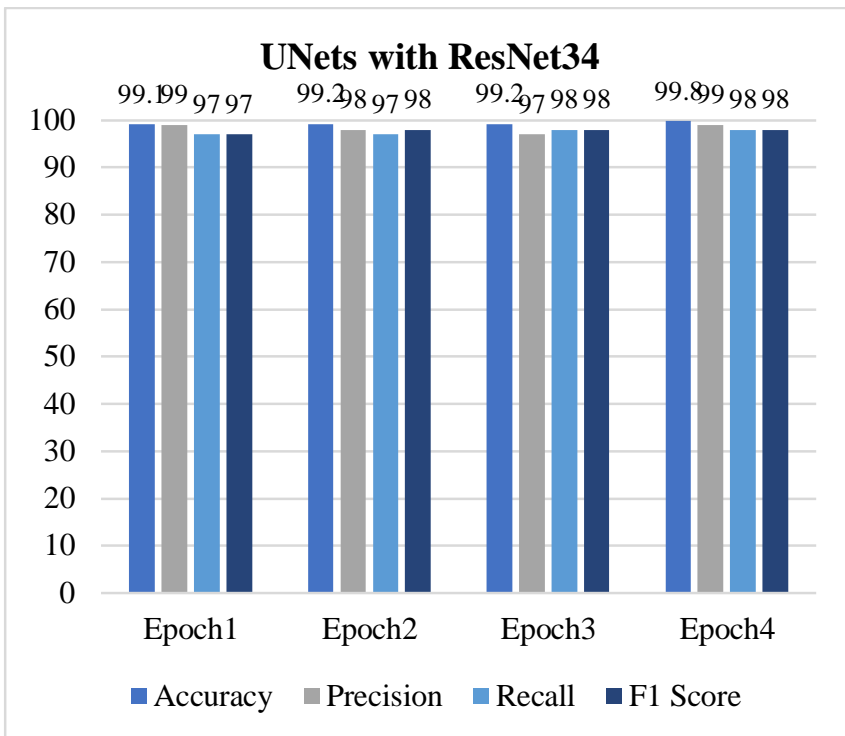

Figure 16 UNets with ResNet34

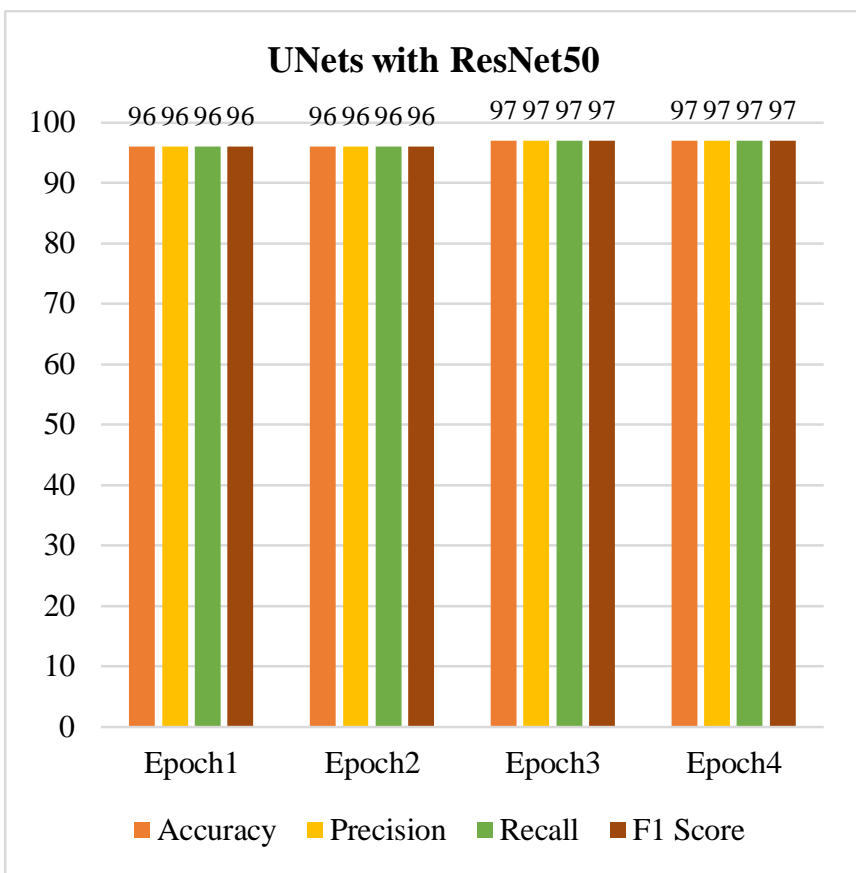

Figure 17 Performance of UNets with ResNet50 
International Journal of Engineering Applied Sciences and Technology, 2021

Vol. 6, Issue 4, ISSN No. 2455-2143, Pages 124-136

Published Online August 2021 in IJEAST (http://www.ijeast.com)

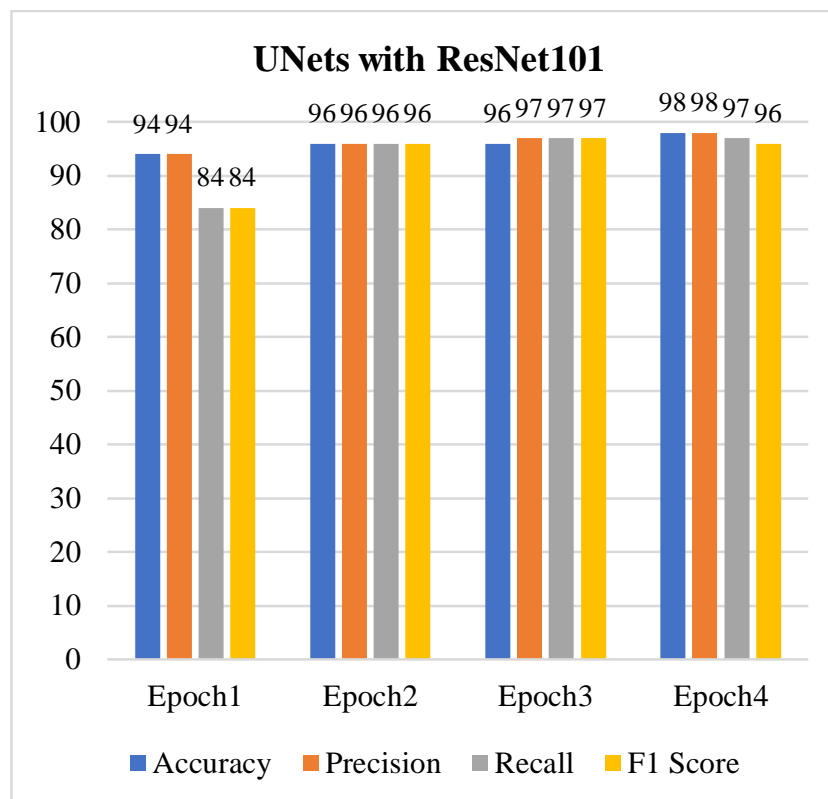

Figure 18 Performance of UNets with ResNet101

The comparison of this study has been summaries with previous research. It can be seen that the current research is the most efficient research in terms of accuracy.

Table 4 Comparison with Previous Studies

\begin{tabular}{|c|c|c|c|c|c|}
\hline Ref & $\begin{array}{l}\text { Techniqu } \\
\mathrm{e}\end{array}$ & Dataset & $\begin{array}{l}\text { Parame } \\
\text { ters }\end{array}$ & $\begin{array}{l}\text { End } \\
\text { Result }\end{array}$ & $\begin{array}{l}\text { Accur } \\
\text { acy }\end{array}$ \\
\hline$[20]$ & $\begin{array}{l}\mathrm{ABCD} \\
\text { rule }\end{array}$ & $\begin{array}{l}\text { Liver- } \\
\text { Tumor- } \\
\text { Segment } \\
\text { ation }\end{array}$ & $\begin{array}{l}\text { Accura } \\
\text { cy }\end{array}$ & $\begin{array}{l}\text { Liver } \\
\text { tumors. }\end{array}$ & $89 \%$ \\
\hline$[21]$ & $\begin{array}{l}\text { CNN, } \\
\text { GAN }\end{array}$ & $\begin{array}{l}\text { Liver- } \\
\text { Tumor- } \\
\text { Segment } \\
\text { ation }\end{array}$ & $\begin{array}{l}\text { Accura } \\
\text { cy }\end{array}$ & $\begin{array}{l}\text { Liver } \\
\text { tumor. }\end{array}$ & $89 \%$ \\
\hline [22] & $\mathrm{CNN}$ & $\begin{array}{l}\text { Liver- } \\
\text { Tumor- } \\
\text { Segment } \\
\text { ation }\end{array}$ & $\begin{array}{l}\text { Accura } \\
\text { cy, } \\
\text { Sensitiv } \\
\text { ity, } \\
\text { Specifi } \\
\text { city, } \\
\text { Predicti } \\
\text { on }\end{array}$ & $\begin{array}{l}\text { Malignan } \\
\mathrm{t} \\
\text { Hepatom } \\
\text { a }\end{array}$ & $89.5 \%$ \\
\hline [38] & $\begin{array}{l}\text { TL, CNN, } \\
\text { SVM }\end{array}$ & $\begin{array}{l}\text { Liver- } \\
\text { Tumor- } \\
\text { Segment } \\
\text { ation }\end{array}$ & $\begin{array}{l}\text { Accura } \\
\text { cy, } \\
\text { Sensitiv } \\
\text { ity, } \\
\text { Specifi } \\
\text { city }\end{array}$ & $\begin{array}{l}\text { Predictio } \\
\mathrm{n} \text { of liver } \\
\text { tumor. }\end{array}$ & $91 \%$ \\
\hline [39] & DL & $\begin{array}{l}\text { Liver- } \\
\text { Tumor- } \\
\text { Segment } \\
\text { ation }\end{array}$ & AUC & $\begin{array}{l}\text { Liver } \\
\text { Cancer. }\end{array}$ & $93.4 \%$ \\
\hline [40] & $\begin{array}{l}\text { CNN, } \\
\text { AlexNet, } \\
\text { VGG16, } \\
\text { ResNet- } \\
50 \text { SVM }\end{array}$ & $\begin{array}{l}\text { Liver- } \\
\text { Tumor- } \\
\text { Segment } \\
\text { ation }\end{array}$ & ROC & $\begin{array}{l}\text { liver } \\
\text { tumors }\end{array}$ & $96 \%$ \\
\hline [23] & $\mathrm{CNN}$ & $\begin{array}{l}\text { Liver- } \\
\text { Tumor- }\end{array}$ & $\begin{array}{l}\text { Sensitiv } \\
\text { ity, }\end{array}$ & $\begin{array}{l}\text { Liver } \\
\text { tumor. }\end{array}$ & $92 \%$ \\
\hline
\end{tabular}

\begin{tabular}{|c|c|c|c|c|c|}
\hline & & $\begin{array}{l}\text { Segment } \\
\text { ation }\end{array}$ & $\begin{array}{l}\text { Specifi } \\
\text { city and } \\
\text { F1 } \\
\text { Score }\end{array}$ & & \\
\hline$[26]$ & CNN & $\begin{array}{l}\text { Liver- } \\
\text { Tumor- } \\
\text { Segment } \\
\text { ation }\end{array}$ & $\begin{array}{l}\text { Accura } \\
\text { cy }\end{array}$ & $\begin{array}{l}\text { Liver } \\
\text { tumors. }\end{array}$ & $86.4 \%$ \\
\hline [24] & $\begin{array}{l}\text { CNN, } \\
\text { Image } \\
\text { warping }\end{array}$ & $\begin{array}{l}\text { Liver- } \\
\text { Tumor- } \\
\text { Segment } \\
\text { ation }\end{array}$ & $\begin{array}{l}\text { Accura } \\
\text { cy }\end{array}$ & $\begin{array}{l}\text { Hepatom } \\
\text { a } \\
\text { classifica } \\
\text { tion. }\end{array}$ & $\begin{array}{l}96.34 \\
\%\end{array}$ \\
\hline [29] & $\begin{array}{l}\text { Fully } \\
\text { Convoluti } \\
\text { onal } \\
\text { Network } \\
\text { (FCN) }\end{array}$ & $\begin{array}{l}\text { Liver- } \\
\text { Tumor- } \\
\text { Segment } \\
\text { ation }\end{array}$ & $\begin{array}{l}\text { Accura } \\
\text { cy, } \\
\text { AUC, } \\
\text { recall }\end{array}$ & $\begin{array}{l}\text { Liver } \\
\text { tumors. }\end{array}$ & $98.9 \%$ \\
\hline [30] & $\begin{array}{l}\text { CNN, } \\
\text { SVM }\end{array}$ & $\begin{array}{l}\text { Liver- } \\
\text { Tumor- } \\
\text { Segment } \\
\text { ation }\end{array}$ & AUC & $\begin{array}{l}\text { Liver } \\
\text { tumor } \\
\text { classifica } \\
\text { tion. }\end{array}$ & $98 \%$ \\
\hline [31] & $\begin{array}{l}\text { CNN, } \\
\text { ssDAAE, } \\
\text { sAAE, } \\
\text { sDAAE } \\
\text { and } \\
\text { ssAAE }\end{array}$ & $\begin{array}{l}\text { Liver- } \\
\text { Tumor- } \\
\text { Segment } \\
\text { ation }\end{array}$ & $\begin{array}{l}\text { RSD, } \\
\text { AUC }\end{array}$ & $\begin{array}{l}\text { Benign } \\
\text { and } \\
\text { malignan } \\
\mathrm{t} \quad \text { liver } \\
\text { tumor. }\end{array}$ & $90 \%$ \\
\hline [41] & $\begin{array}{l}\text { CNN, } \\
\text { DL, TL }\end{array}$ & $\begin{array}{l}\text { Liver- } \\
\text { Tumor- } \\
\text { Segment } \\
\text { ation }\end{array}$ & $\begin{array}{l}\text { F1- } \\
\text { Score, } \\
\text { Recall, } \\
\text { Precisio } \\
\text { n, } \\
\text { Accura } \\
\text { cy. }\end{array}$ & $\begin{array}{l}\text { Liver } \\
\text { tumors. }\end{array}$ & $96 \%$ \\
\hline [42] & $\begin{array}{l}\text { DL, TL, } \\
\text { Softmax, } \\
\text { AlexNet }\end{array}$ & $\begin{array}{l}\text { Liver- } \\
\text { Tumor- } \\
\text { Segment } \\
\text { ation }\end{array}$ & $\begin{array}{l}\text { Accura } \\
\text { cy, } \\
\text { specific } \\
\text { ity and } \\
\text { sensitiv } \\
\text { ity }\end{array}$ & $\begin{array}{l}\text { Hepatom } \\
\text { a Liver } \\
\text { Cancer. }\end{array}$ & $94 \%$ \\
\hline [43] & $\begin{array}{l}\text { MobileNe } \\
\text { t }\end{array}$ & $\begin{array}{l}\text { Liver- } \\
\text { Tumor- } \\
\text { Segment } \\
\text { ation }\end{array}$ & $\begin{array}{l}\text { AUC } \\
\text { and } \\
\text { accurac } \\
\text { y }\end{array}$ & $\begin{array}{l}\text { Liver } \\
\text { diseases. }\end{array}$ & $95 \%$ \\
\hline $\begin{array}{l}\text { Our } \\
\text { Propo } \\
\text { sed }\end{array}$ & $\begin{array}{l}\text { UNets } \\
\text { with } \\
\text { ResNet }\end{array}$ & $\begin{array}{l}\text { Liver- } \\
\text { Tumor- } \\
\text { Segment } \\
\text { ation }\end{array}$ & $\begin{array}{l}\text { Accura } \\
\text { cy }\end{array}$ & $\begin{array}{l}\text { Liver } \\
\text { Lesion } \\
\text { Cancerou } \\
\text { s Tumor } \\
\end{array}$ & $99.8 \%$ \\
\hline
\end{tabular}

\section{CONCLUSION}

In this research work, we proposed an automated and intelligent system for the detection of liver tumors with a special focus on malignant Hepatoma. We split the dataset into Train/test/validation split with a ratio of 70 percent $/ 24$ percent $/ 6$ percent. Since the dataset I used is imbalanced, so I augmented the training data using the slicing multiplier. After slicing, the total number of train images becomes 130 . Then, we append the original and augmented data and the total images become in the training data became 20. We have used the FASTAI and UNets model. We train the model on our training data and found the learning rate of the model. Then I estimated the confusion matrix and accuracy of the trained model. Top- 5 accuracies of our trained model range from $98-99.8 \%$ and that are considered 


\section{International Journal of Engineering Applied Sciences and Technology, 2021 \\ Vol. 6, Issue 4, ISSN No. 2455-2143, Pages 124-136 \\ Published Online August 2021 in IJEAST (http://www.ijeast.com)}

as the best accuracy. We tested the model by providing the random test images one by one and estimate the confidence level of prediction of the model. The model predicted the Hepatoma with confidence level ranges from 70-100\% depending on the resolution of the image. For future work, one can suggest the implementation of this automated method for the detection of liver tumors into smartphones/Tabs. We can also optimize the learning rate of the classifiers. Hepatomic images can be sliced into layers so that more accurate detection may perform at higher accuracy.

\section{REFERENCE}

[1] D. Schadendorf et al., "Melanoma," Lancet, vol. 392, no. 10151, pp. 971-984, 2018, doi: 10.1016/S01406736(18)31559-9.

[2] U. Dafni, Z. Tsourti, and I. Alatsathianos, "Breast cancer statistics in the european union: Incidence and survival across european countries," Breast Care, vol. 14, no. 6, pp. 344-353, 2019, doi: 10.1159/000503219.

[3] P. Cancer, R. Method, and M. Country-specific, "200 813 816," vol. 066, pp. 2018-2019, 2019.

[4] C. Joachim et al., "Cancer burden in the Caribbean: An overview of the Martinique Cancer Registry profile," BMC Cancer, vol. 19, no. 1, pp. 1-9, 2019, doi: 10.1186/s12885-019-5434-6.

[5] R. L. Siegel, K. D. Miller, and A. Jemal, "Cancer statistics, 2016," CA. Cancer J. Clin., vol. 66, no. 1, pp. 7-30, 2016, doi: 10.3322/caac.21332.

[6] L. A. Torre, A. M. G. Sauer, M. S. Chen, M. KagawaSinger, A. Jemal, and R. L. Siegel, "Cancer statistics for Asian Americans, Native Hawaiians, and Pacific Islanders, 2016: Converging incidence in males and females," CA. Cancer J. Clin., vol. 66, no. 3, pp. 182202, 2016, doi: 10.3322/caac. 21335.

[7] A. AhmedK, S. Aljahdali, and S. Naimatullah Hussain, "Comparative Prediction Performance with Support Vector Machine and Random Forest Classification Techniques," Int. J. Comput. Appl., vol. 69, no. 11, pp. 12-16, 2013, doi: 10.5120/11885-7922.

[8] A. Zink, M. Schielein, M. Wildner, and E. A. Rehfuess, "“Try to make good hay in the shade - it won't work!' A qualitative interview study on the perspectives of Bavarian farmers regarding primary prevention of skin cancer," Br. J. Dermatol., vol. 180, no. 6, pp. 14121419, 2019, doi: 10.1111/bjd.17872.

[9] T. Round, C. Gildea, M. Ashworth, and H. Møller, "Association between use of urgent suspected cancer referral and mortality and stage at diagnosis: A 5-year national cohort study," Br. J. Gen. Pract., vol. 70, no. 695, pp. E389-E398, 2020, doi: 10.3399/bjgp20X709433.

[10] M. Morris, S. Landon, I. Reguilon, J. Butler, M. McKee, and E. Nolte, "Understanding the link between health systems and cancer survival: A novel methodological approach using a system-level conceptual model," J. Cancer Policy, vol. 25, no. May, p. 100233, 2020, doi: 10.1016/j.jcpo.2020.100233.

[11] D. Bisla, A. Choromanska, R. S. Berman, J. A. Stein, and D. Polsky, "Towards automated melanoma detection with deep learning: Data purification and augmentation," IEEE Comput. Soc. Conf. Comput. Vis. Pattern Recognit. Work., vol. 2019-June, pp. 2720 2728, 2019, doi: 10.1109/CVPRW.2019.00330.

[12] B. J. Erickson, P. Korfiatis, Z. Akkus, and T. L. Kline, "Machine Learning for Medical," no. 1, pp. 505-515, 2017.

[13] M. Gaana, S. Gupta, and N. S. Ramaiah, "Diagnosis of Skin Cancer Melanoma using Machine Learning," SSRN Electron. J., no. 2015, 2020, doi: 10.2139/ssrn.3358134.

[14] A. Narin, C. Kaya, and Z. Pamuk, "Department of Biomedical Engineering, Zonguldak Bulent Ecevit University, 67100, Zonguldak, Turkey.," arXiv Prepr. arXiv2003.10849., 2020, [Online]. Available: https://arxiv.org/abs/2003.10849.

[15] Y. Zhang et al., "Little egrets (Egretta Garzetta) and trace-metal contamination in wetlands of China," Environ. Monit. Assess., vol. 118, no. 1-3, pp. 355-368, 2006, doi: 10.1007/s10661-006-1496-4.

[16] A. Rashid and M. Asim Mahmood, "Linguistic Variations across Disciplines: A Multidimensional Analysis of Pakistani Research Articles," Glob. Soc. Sci. Rev., vol. IV, no. I, pp. 23-33, 2019, doi: 10.31703/gssr.2019(iv-i).04.

[17] Q. Ain et al., "a Technique To Increase the Usability of E-Learning Websites," Pak. J. Sci., vol. 68, no. 2, 2016.

[18] S. Ahmad, "A Review of COVID-19 (Coronavirus Disease-2019) Diagnosis, Treatments and Prevention," Eurasian J. Med. Oncol., vol. 4, no. 2, pp. 116-125, 2020, doi: 10.14744/ejmo.2020.90853.

[19] S. Sofia et al., "Thoracic ultrasound and SARSCOVID-19: a pictorial essay," J. Ultrasound, vol. 23, no. 2, pp. 217-221, 2020, doi: 10.1007/s40477-02000458-7.

[20] N. S. Zghal and N. Derbel, "Melanoma Skin Cancer Detection based on Image Processing," Curr. Med. Imaging Former. Curr. Med. Imaging Rev., vol. 16, no. 1, pp. 50-58, Jan. 2020, doi: 10.2174/1573405614666180911120546.

[21] P. Sedigh, R. Sadeghian, and M. T. Masouleh, "Generating Synthetic Medical Images by Using GAN to Improve CNN Performance in Skin Cancer Classification," in ICRoM 2019 - 7th International Conference on Robotics and Mechatronics, Nov. 2019, pp. 497-502, doi: 10.1109/ICRoM48714.2019.9071823.

[22] R. Amalia Pratiwi, S. Nurmaini, and D. Palupi Rini, "Skin Lesion Classification Based on Convolutional Neural Networks," Comput. Eng. Appl., vol. 8, no. 3, p. 


\section{International Journal of Engineering Applied Sciences and Technology, 2021 \\ Vol. 6, Issue 4, ISSN No. 2455-2143, Pages 124-136 \\ Published Online August 2021 in IJEAST (http://www.ijeast.com)}

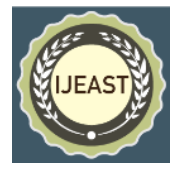

203, 2019.

[23] W. Sae-lim, W. Wettayaprasit, and P. Aiyarak, "Convolutional Neural Networks Using MobileNet for Skin Lesion Classification," pp. 242-247, 2019.

[24] C. N. Vasconcelos and B. N. Vasconcelos, "Convolutional Neural Network Committees for Melanoma Classification with Classical And Expert Knowledge Based Image Transforms Data Augmentation," 2017.

[25] "ISBI 2016, The International Symposium on Biomedical Imaging." .

[26] F. Sherif, W. A. Mohamed, and A. S. Mohra, "Skin lesion analysis toward melanoma detection using deep learning techniques," Int. J. Electron. Telecommun., vol. 65, no. 4, pp. 597-602, 2019, doi: 10.24425/ijet.2019.129818.

[27] "ISIC Archive.".

[28] "Is this the end? Machine learning and 2 other threats to radiology's future." .

[29] A. A. Adegun and S. Viriri, "FCN-Based DenseNet Framework for Automated Detection and Classification of Skin Lesions in Dermoscopy Images," IEEE Access, vol. 8, pp. 150377-150396, 2020, doi: 10.1109/ACCESS.2020.3016651.

[30] A. Menegola, J. Tavares, M. Fornaciali, L. T. Li, S. Avila, and E. Valle, "RECOD Titans at ISIC Challenge 2017," pp. 1-5, 2017.

[31] A. Creswell, A. Pouplin, and A. A. Bharath, "Denoising adversarial autoencoders: Classifying skin lesions using limited labelled training data," IET Comput. Vis., vol. 12 , no. 8, pp. 1105-1111, 2018, doi: 10.1049/ietcvi.2018.5243.

[32] R. Cui, A. Zhu, J. Wu, and G. Hua, "Skeleton-based attention-aware spatial-temporal model for action detection and recognition," IET Comput. Vis., vol. 14, no. 5, pp. 177-184, Aug. 2020, doi: 10.1049/ietcvi.2019.0751.

[33] Y. Jiang, H. Chen, M. Loew, and H. Ko, "COVID-19 CT Image Synthesis with a Conditional Generative Adversarial Network," no. 2, pp. 1-11, 2020, [Online]. Available: http://arxiv.org/abs/2007.14638.

[34] R. N. Malik, S. Rauf, A. Mohammad, S. A. M. A. S. Eqani, and K. Ahad, "Organochlorine residual concentrations in cattle egret from the Punjab Province, Pakistan," Environ. Monit. Assess., vol. 173, no. 1-4, pp. 325-341, 2011, doi: 10.1007/s10661-010-1390-y.

[35] P. de L. Sobreira et al., "Usability evaluation of block programming tools in IoT contexts for initial engineering courses," pp. 1-5, 2020, doi: 10.1109/edunine48860.2020.9149481.

[36] C. De Medio, C. Limongelli, F. Sciarrone, and M. Temperini, "MoodleREC: A recommendation system for creating courses using the moodle e-learning platform," Comput. Human Behav., vol. 104, p. 106168, 2020, doi: 10.1016/j.chb.2019.106168.
[37] S. Singh, "Pushing the limits of radiology with joint modeling of visual and textual information," ACL 2018 - 56th Annu. Meet. Assoc. Comput. Linguist. Proc. Student Res. Work., pp. 28-36, 2018, doi: 10.18653/v1/p18-3005.

[38] L. Zhou, Q. Wang, L. Wang, and Y. Shi, "Longitudinal Patch-Based Segmentation of Multiple Sclerosis White Matter Lesions," Lect. Notes Comput. Sci. (including Subser. Lect. Notes Artif. Intell. Lect. Notes Bioinformatics), vol. 9352, no. Mci, pp. 194-202, 2015, doi: 10.1007/978-3-319-24888-2.

[39] M. A. Kadampur and S. Al Riyaee, "Informatics in Medicine Unlocked Skin cancer detection : Applying a deep learning based model driven architecture in the cloud for classifying dermal cell images," Informatics Med. Unlocked, vol. 18, no. November 2019, p. 100282, 2020, doi: 10.1016/j.imu.2019.100282.

[40] A. Mahbod, G. Schaefer, C. Wang, R. Ecker, and I. Ellinger, "Institute for Pathophysiology and Allergy Research , Medical University of Vienna, Austria Department of Research and Development , TissueGnostics GmbH , Austria Department of Computer Science, Loughborough University , U . K . Department of Biomedical ," pp. 1229-1233, 2019.

[41] R. Garg, S. Maheshwari, and A. Shukla, "Decision Support System for Detection and Classification of Skin Cancer using CNN," pp. 1-9, 2019.

[42] K. M. Hosny, M. A. Kassem, and M. M. Foaud, "Skin Cancer Classification using Deep Learning and Transfer Learning," 2018 9th Cairo Int. Biomed. Eng. Conf. CIBEC 2018 - Proc., no. December, pp. 90-93, 2019, doi: 10.1109/CIBEC.2018.8641762.

[43] M. N. Bajwa et al., "Computer-aided diagnosis of skin diseases using deep neural networks," Appl. Sci., vol. 10, no. 7, pp. 1-13, 2020, doi: 10.3390/app10072488.

[44] "2017 IEEE 8th International Conference on Intelligent Computing and Information Systems, ICICIS 2017," 2017 IEEE 8th Int. Conf. Intell. Comput. Inf. Syst. ICICIS 2017, vol. 2018-Janua, no. Icicis, pp. 403-409, 2018.

[45] P. Kharazmi, J. Zheng, H. Lui, Z. Jane Wang, and T. K. Lee, "A Computer-Aided Decision Support System for Detection and Localization of Cutaneous Vasculature in Dermoscopy Images Via Deep Feature Learning," $J$. Med. Syst., vol. 42, no. 2, 2018, doi: 10.1007/s10916017-0885-2.

[46] M. A. Farooq, A. Khatoon, V. Varkarakis, and P. Corcoran, "Advanced deep learning methodologies for skin cancer classification in prodromal stages," CEUR Workshop Proc., vol. 2563, pp. 40-51, 2019.

[47] P. Tschandl, C. Rosendahl, and H. Kittler, "Data descriptor: The HAM10000 dataset, a large collection of multi-source dermatoscopic images of common pigmented skin lesions," Sci. Data, vol. 5, Aug. 2018, doi: 10.1038/sdata.2018.161. 
[48] "Liver Lesions: Types, Causes, Diagnosis \& More." https://www.docpanel.com/blog/post/liver-lesions-

types-causes-diagnosis-more (accessed Mar. 03, 2021).

[49] M. Mendoza and S. Velastín, "Progress in Pattern Recognition, Image Analysis, Computer Vision, and Applications 22nd Iberoamerican Congress, CIARP 2017 Valparaíso, Chile, November 7-10, 2017 Proceedings," vol. 1, no. October, pp. 534-541, 2018, doi: 10.1007/978-3-319-75193-1.

[50] “Add support for torchvision's mobilenet_v2 by rsomani95 · Pull Request \#2456 · fastai/fastai . GitHub.”. 